\title{
Radical cystectomy in elderly patients, single center, 25 years experience
}

\author{
Sacit Nuri Gorgel*, Osman Kose, Ozan Horsanalı, Evren Sahin, Ugur Balci, Kutan Ozer, \\ Cengiz Girgin
}

Izmir Katip Celebi University, Ataturk Training and Reseacrh Hospital, Department of Urology, Izmir, Turkey

Email address:

sngorgel@hotmail.com (S. N. Gorgel)

\section{To cite this article:}

Sacit Nuri Gorgel, Osman Kose, Ozan Horsanalı, Evren Sahin, Ugur Balci, Kutan Ozer, Cengiz Girgin. Radical Cystectomy in Elderly Patients, Single Center, 25 Years Experience. Clinical Medicine Research. Vol. 3, No. 6, 2014, pp. 206-210.

doi: 10.11648/j.cmr.20140306.19

\begin{abstract}
Objectives: To investigate the relation between age and tumor characteristics and to evaluate oncologic results after radical cystectomy in elderly patients. Materials and Methods: We reviewed 501 patients retrospectively who underwent radical cystectomy because of bladder cancer. Patients were divided into two groups; greater than or equal to 70 (group 1) and less than 70-years-old (group 2). We compared tumor pathological characteristics and oncologic results in both groups. American Society of Anesthesiologists (ASA) score is less than three and there was no risk for major surgery for all patients. None of the patients did not receive neoadjuvant radiotherapy and/or chemotherapy. Results: There were 87 (17.4\%) patients in group 1 and $414(82.6 \%)$ patients in group 2. The mean age was 73.3 \pm 3.01 (70-85) in group 1, and 58.3 \pm 7.47 (34-69) in group 2. There were no significantly difference between gender $(0.135)$, pathological $\mathrm{T}$ stage $(\mathrm{p}=0.483)$, lymph node involvement $(\mathrm{p}=0.462)$, grade $(\mathrm{p}=0.522)$, type of diversion $(\mathrm{p}=0.193)$, histological type $(\mathrm{p}=0.656)$ in both groups. Perioperative mortality were $3.9 \%$ in group 1 and $3.4 \%$ in group $2(\mathrm{p}=0.218)$. Perioperative complication rates were $16.6 \%$ in group 1 and $17.4 \%$ in group $2(\mathrm{p}=0.469)$. Five years disease specific survival (DSS) rates were $61 \%$ in group 1 and $53 \%$ in group 2 (p=0.936). The mean DSS periods were $72.91 \pm 5.35$ months in group 1 and $76.25 \pm 7.45$ months in group 2 . Five years overall survival rates were $43.9 \%$ in group $1,45.9 \%$ in group $2(\mathrm{p}=0.476)$. Mean overall survival periods were $54.02 \pm 8.47$ in group 1 and $69.25 \pm 4.97$ in group 2. In cox regression analyse; tumor stage $(\mathrm{p}=0.012)$ and lymph node involvement $(\mathrm{p}<0.001)$ were significant factors affected the survival in both groups. Conclusions: We found similar oncological results in patients who underwent radical cystectomy because of bladder cancer between young and elderly patients. We believe that age is not a contraindication factor for radical cystectomy operation. In addition preoperative performance statue of patients is important in terms of perioperative complications and mortality.
\end{abstract}

Keywords: Bladder Cancer, Elderly, Radical Cystectomy

\section{Introduction}

Cancer is the major cause of death and morbidity in the elderly. The proportion of elderly people in the general population is increasing. The increase in lifespan is associated with an increase in the incidence of some tumors including bladder cancer $(1,2)$. Among people in the eighth decade, bladder cancer is the fifth leading cause of cancer death (1). Radical cystectomy is the treatment of choice for patients with invasive bladder cancer. Co-morbidity and unique physiological changes present a surgical challenge in the elderly patient $(1,2)$.

Bladder cancer is the ninth most common cancer diagnosis worldwide, with more than 330,000 new cases each year and more than 130,000 deaths per year, with an estimated malefemale ratio of 3.8:1.0. At any point in time, 2.7 million people have a history of urinary bladder cancer (3). At the initial diagnosis of bladder cancer, $70 \%$ of cases are diagnosed as non-muscle-invasive bladder cancer and approximately $30 \%$ as muscle-invasive bladder cancer (4).

Traditionally, radical cystectomy was recommended for patients with muscle invasive bladder cancer T2-T4a, N0-Nx, M0. Other indications include high-risk and recurrent superficial tumours, BCG-resistant Tis, T1G3, as well as 
extensive papillary disease that cannot be controlled with TUR and intravesical therapy alone (5).

The American Society of Anaesthesiologists' (ASA) risk classification system is actually an index for perioperative risk, but it can also be used to evaluate comorbidity because it describes a patient's physical status prior to surgery (6). The current ASA classification was developed in 1941 by Meyer Saklad (7) Several other small series have also failed to demonstrate any association between ASA class and clinical outcome after cystectomy $(8,9)$.

In this study we aimed to investigate the relation between age and tumor characteristics and to evaluate oncologic results after radical cystectomy in elderly patients with ASA score less than three.

\section{Materials and Methods}

We reviewed 501 patients retrospectively who underwent radical cystectomy because of bladder cancer. Patients were divided into two groups; greater than or equal to 70 (group 1) and less than 70-years-old (group 2). We compared tumor pathological characteristics and oncologic results in both groups. ASA score is less than three and there was no risk for major surgery for all patients. None of the patients did not receive neoadjuvant radiotherapy and/or chemotherapy.

\section{Statistical Analysis}

Quantitative data were expressed as means \pm standard deviations. Chi-Square Tests were used to compare nonparametric values. Kaplan-Meier survival curves were used to estimate disease-specific survival (DSS) and overall survival (OAS) according to age. Cox regression was performed to define independent factors associated with survival. p-value less than 0.05 was considered significant. All statistical analyses were performed by using the SPSS ver. 16.0 (SPSS Inc., Chicago, IL, USA).

\section{Results}

There were $87(17.4 \%)$ patients in group 1 and $414(82.6 \%)$ patients in group 2 . The mean age was $73.3 \pm 3.01(70-85)$ in group 1, and $58.3 \pm 7.47$ (34-69) in group 2. There were no significantly difference between gender $(0.135)$, pathological $\mathrm{T}$ stage $(\mathrm{p}=0.483)$, lymph nodes involvement $(\mathrm{p}=0.462)$, grade $(\mathrm{p}=0.522)$, type of diversion $(\mathrm{p}=0.193)$, histological type $(\mathrm{p}=0.656)$ in both groups.

Perioperative mortality were $3.9 \%$ in group 1 and $3.4 \%$ in group $2(\mathrm{p}=0.218)$. Perioperative complication rates were $16.6 \%$ in group 1 and $17.4 \%$ in group $2(\mathrm{p}=0.469)$. Patient demographics and clinico-pathological characteristics were demonstrated in Table1.

Five years DSS rates were $61 \%$ in group 1 and $53 \%$ in group $2(p=0.936)$ (Figure 1$)$. The mean DSS periods were
$72.91 \pm 5.35$ months in group 1 and $76.25 \pm 7.45$ months in group 2. Five years overall survival rates were $43.9 \%$ in group $1,45.9 \%$ in group $2(\mathrm{p}=0.476)$ (Figure 2). Mean overall survival periods were $54.02 \pm 8.47$ in group 1 and $69.25 \pm 4.97$ in group 2 .

In cox regression analyse; tumor stage $(p=0.012)$ and lymph node involvement $(\mathrm{p}<0.001)$ were significant factors affected the survival in both groups.

Table 1. Demographics and clinico-pathological characteristics of patients.

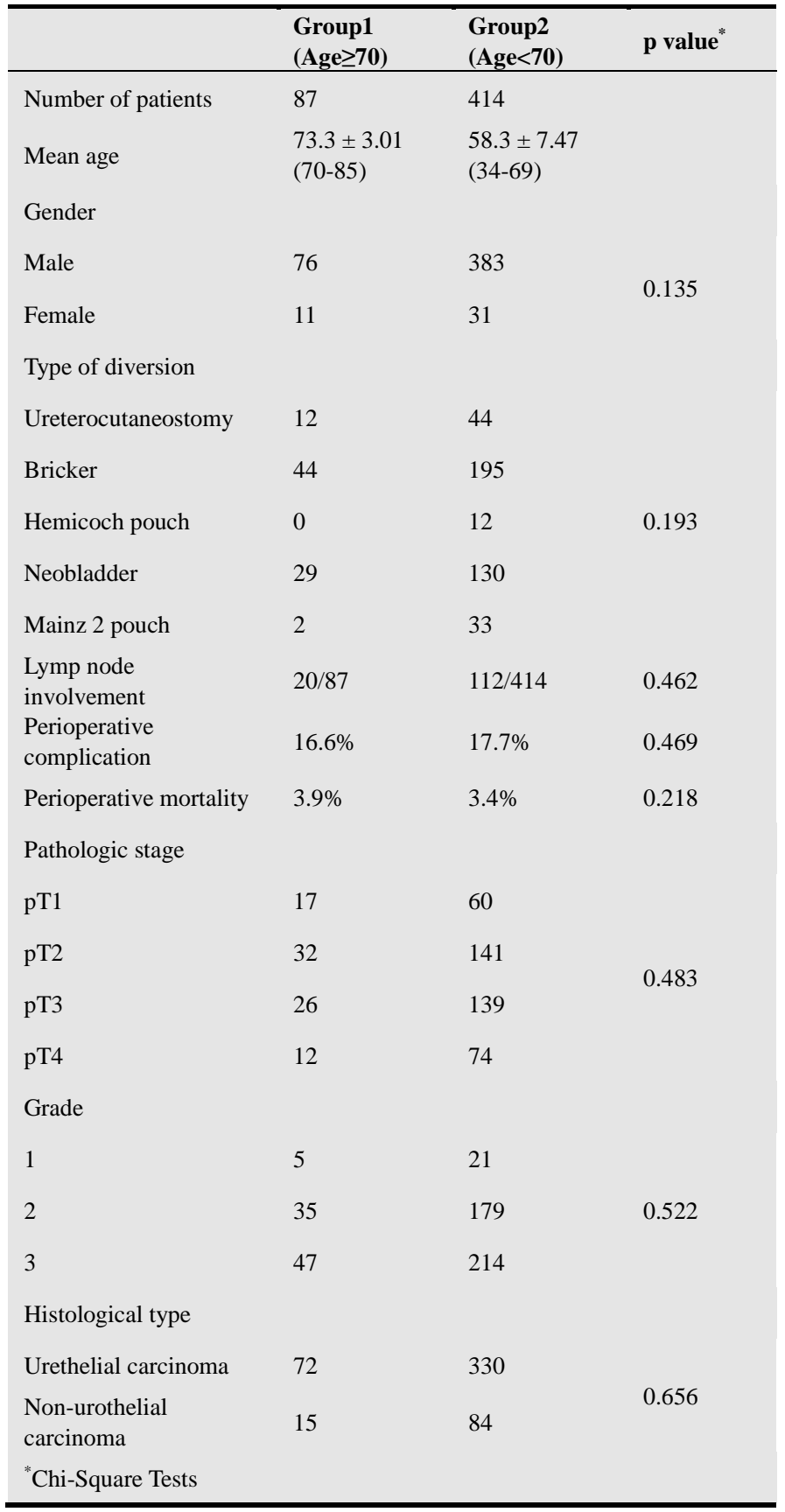




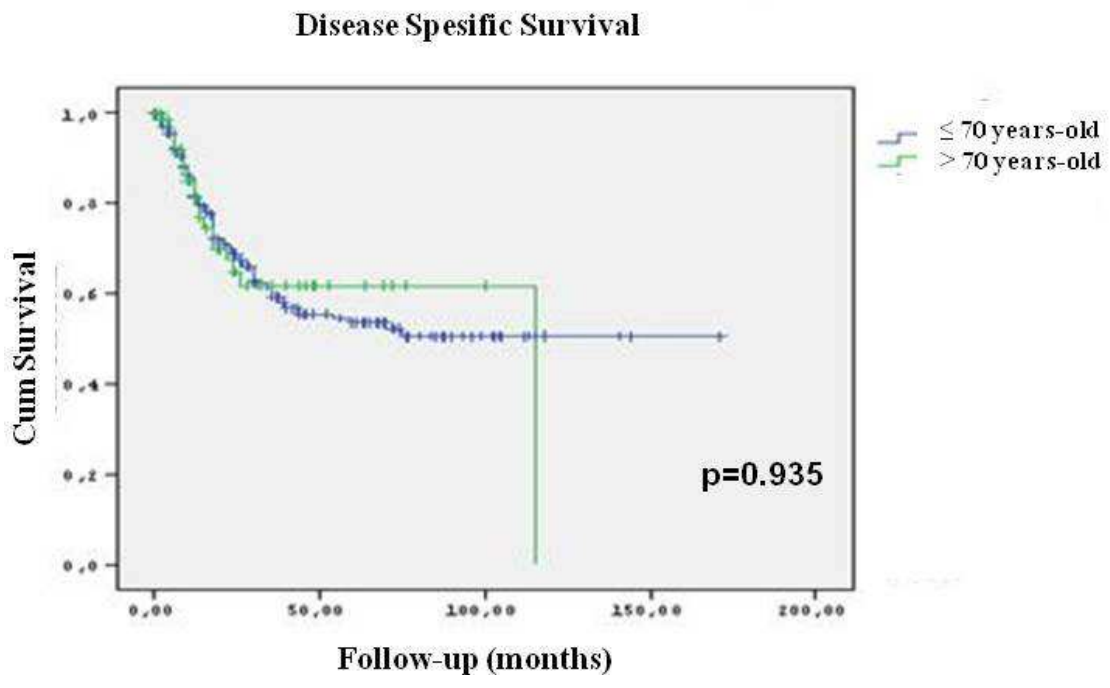

Figure 1. Disease specific survival for both groups.

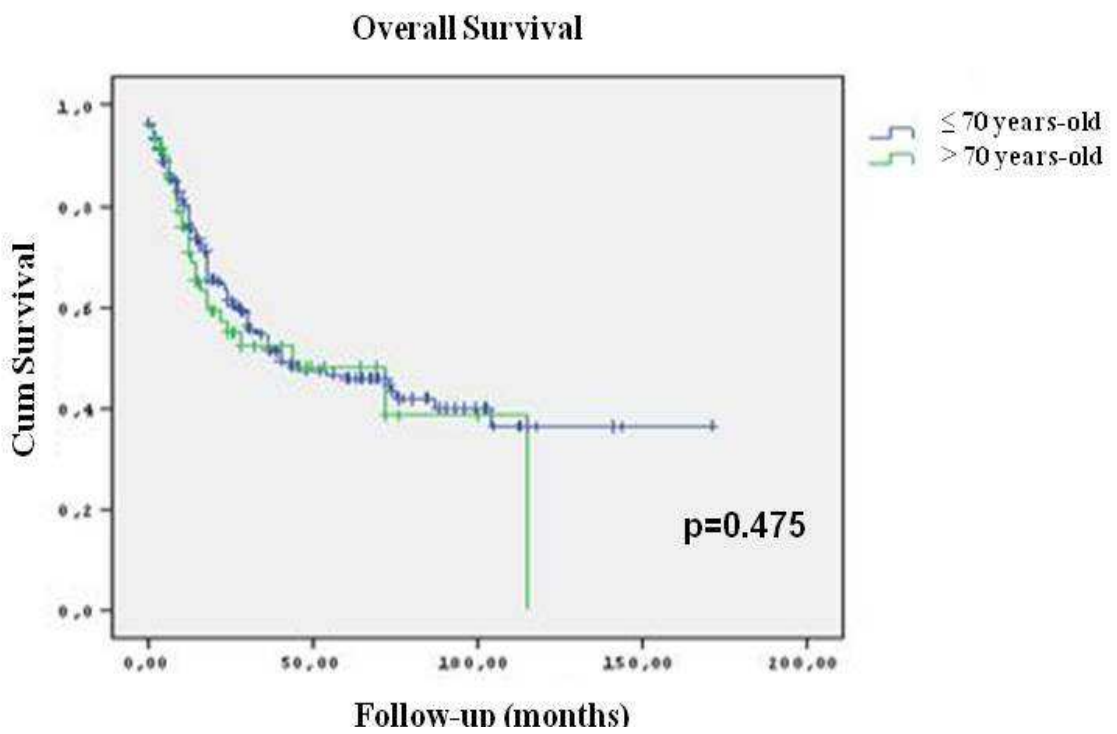

Figure 2. Disease specific survival for both groups.

\section{Discussion}

Bladder cancer is a common malignancy that disproportionately affects the elderly. The National Cancer Institute (NCI) Surveillance, Epidemiology, and End Results (SEER) Program estimated that most bladder carcinoma patients are 65 years or older at the time of diagnosis, and that the median age at diagnosis is 73 years (10). In the United States, bladder cancer is the fourth leading cause of cancer-related mortality in men aged 80 years or older (11).

Radical cystectomy is the standard treatment for localised muscle invasive bladder cancer in most western countries $(12,13)$. Recent interest in patients' quality of life has increased the trend toward bladder preservation treatment modalities, such as radio- and/or chemotherapy. Performance status and age influence the choice of primary therapy, as well as the type of urinary diversion, with cystectomy being reserved for younger patients without concomitant disease and with a better performance status. The value of assessing overall health before recommending and proceeding with surgery was emphasised in a multivariate analysis (14). The analysis found an association between comorbidity and adverse pathological and survival outcome following radical cystectomy (14). Performance status and comorbidity have a different impact on treatment outcome and must be evaluated independently (15).

Controversy remains about age, radical cystectomy and the type of urinary diversion. Cystectomy is associated with the greatest risk reduction in disease-related and non-diseaserelated death in patients aged $>80$ years (14). The largest, retrospective, single-institution study on cystectomy to date found that patients aged $>80$ years had increased postoperative morbidity but not increased mortality. Although some patients successfully underwent a neobladder procedure, most patients were treated with an ileal conduit diversion (16). It is particularly important to evaluate the function and quality of life elderly patients using a standardised geriatric assessment, as well as carrying out a 
standard medical evaluation (17).

Age is often a major consideration when considering treatment options for muscle invasive bladder cancer. Data from multiple small surgical series have demonstrated that selected older patients were comparable to their younger counterparts in terms of early and late complications and perioperative outcomes $(1,9,18)$. However, other reports suggested that advanced age may be an independent predictor of adverse oncologic and overall survival outcomes $(19,20)$. In the present study, there was no significantly different in terms of perioperative complications and mortality. This condition can be explained by lower ASA score. Furthermore oncologic features such as pathologic stage and grade in both groups.

According to Surveillance,Epidemiology and End Results data, disease-specific survival after radical cystectomy appears to be influenced only by disease-related factors (stage and extent of lymphadenectomy), and not by age (21). In our study tumor stage and lymph node involvement were significant factors affected negatively the survival in both groups.

Radical cystectomy is associated with major morbidity and mortality. The early postoperative complication rate ranges from 25 to $57 \%(22,23)$ and early mortality rate is about $3 \%$ (24), and is even higher in elderly patients (25). In a review of the literature by Peyromaure et al. ${ }^{2}$, the early mortality rate after cystectomy in patients over 70 years old ranged from 0 $-4.5 \%$, and these results were similar to those in a younger population. The overall peri-operative complications ranged from $61-70 \%$ which were mostly anesthetic. The overall postoperative complications ranged from 28-64\% which again were mostly medical $(41-72 \%)$ like in other series.

Perioperative mortality was $3.9 \%$ in group 1 and $3.4 \%$ in group 2. Perioperative complication rates were $16.6 \%$ in group 1 and $17.4 \%$ in group 2 . In our series, most common perioperative complications were ileus and urinary tract infections

Several investigators like Nielson et al, found that advanced age was associated with extravesical disease, upstaging from clinical to pathologic stage and cancerspecific mortality in patients treated with radical cystectomy (26) and elderly patients were less likely to be treated with extirpative surgery than their younger counterparts (27) In our study, we found similar pathologic stage and grade between younger and elderly patients.

The current study was limited by its retrospective design and small number of patients for elderly patients.

\section{Conclusion}

The number of elderly people in the total population is rising. We found similar oncological results in patients who underwent radical cystectomy because of bladder cancer between young and elderly patients. Our series demonstrates that cystectomy with urinary diversion can be safely performed in the elderly with acceptable morbidity and mortality.

\section{References}

[1] Stroumbakis N, Herr HW, Cookson MS, Fair WR. Radical Cystectomy in the octogenarian. J Urol. 1997; 158 (6): 2113-7.

[2] Peyromaure M, Guerin F, Debre B, Zerbib M. Surgical management of infiltrating bladder cancer in elderly patients. Eur Urol. 2004; 45 (2): 147-54.

[3] Ploeg M, Aben KK, Kiemeney LA. The present and future burden of urinary bladder cancer in the world. World J Urol. 2009; 27(3): 289-93.

[4] Vaidya A, Soloway MS, Hawke C, Tiguert R, Civantos F. De novo muscle invasive bladder cancer: is there a change in trend? J Urol. 2001; 165(1): 47-50.

[5] J.A. Witjes (chair), E. Compérat, N.C. Cowan, M. De Santis, G. Gakis, T. Lebret et al. Guidelines on Muscle-invasive and Metastatic Bladder Cancer. European Association of Urology. 2013 p34.

[6] Ferrier MB, Spuesens EB, Le Cessie S, Baatenburg de Jong RJ. Comorbidity as a major risk factor for mortality and complications in head and neck surgery. Arch Otolaryngol Head Neck Surg. 2005; 131(1): 27-32.

[7] Saklad M. Grading of patients for surgical procedures. Anesthesiology. 1941; 2(3): 281-5.

[8] Jensen J, Pedersen K, Olsen K, Bisgaard U, Jensen K. Minilaparotomy approach to radical cystectomy. BJU Int. 2011; 108: 1125-1130.

[9] Chang SS, Alberts G, Cookson MS, Smith JA Jr. Radical cystectomy is safe in elderly patients at high risk. J Urol. 2001; 166(3): 938-41.

[10] Altekruse SF KC, Krapcho M, Neyman N, Animou R, Waldron W, Ruhl J, et al. SEER Cancer Statistics Review, 1975-2007. 2011

[11] Jemal A, Siegel R, Xu J, Ward E. Cancer statistics, 2010. CA Cancer J Clin. 2010; 60(5): 277-300.

[12] World Health Organization (WHO) Consensus Conference in Bladder Cancer, Hautmann RE, AbolEnein H, Hafez K, Haro I, Mansson W, Mills RD, Montie JD, Sagalowsky AI, Stein JP, Stenzl A, Studer UE, Volkmer BG. Urinary diversion. Urology 2007 Jan; 69(1 Suppl):17-49.

[13] Stein JP, Lieskovsky G, Cote R, et al. Radical cystectomy in the treatment of invasive bladder cancer: long-term results in 1,054 patients. J Clin Oncol 2001 Feb;19(3):666-75.

[14] Miller DC, Taub DA, Dunn RL, et al. The impact of comorbid disease on cancer control and survival following radical cystectomy. J Urol 2003 Jan;169(1):105-9.

[15] Extermann M, Overcash J, Lyman GH, et al. Comorbidity and functional status are independent in older cancer patients. J Clin Oncol 1998 Apr;16(4):1582-7.

[16] Figueroa AJ, Stein JP, Dickinson M, et al. Radical cystectomy for elderly patients with bladder carcinoma: an updated experience with 404 patients. Cancer $1998 \mathrm{Jul} ; 83(1): 141-7$.

[17] Geriatric Assessment Methods for Clinical Decision making. NIH Consensus Statement Online 1987 Oct Online 19-21 [cited $2013 \mathrm{Feb}, 6$ th];6(13):1-21 
[18] Soulié M, Straub M, Gamé X, Seguin P, De Petriconi R, Plante $\mathrm{P}$, et al. A multicenter study of the morbidity of radical cystectomy in select elderly patients with bladder cancer. J Urol. 2002; 167(3): 1325-1328.

[19] Clark PE, Stein JP, Groshen SG, Cai J, Miranda G, Lieskovsky $\mathrm{G}$, et al. Radical cystectomy in the elderly: comparison of clincal outcomes between younger and older patients. Cancer. 2005; 104(1): 36-43.

[20] Nielsen ME, Shariat SF, Karakiewicz PI, Lotan Y, Rogers CG, Amiel GE, et al. Advanced age is associated with poorer bladder cancer-specific survival in patients treated with radical cystectomy. Eur Urol. 2007; 51(3): 699-706.

[21] Konety BR, Joslyn SA. Factors influencing aggressive therapy for bladder cancer: An analysis data from the SEER program. J Urol. 2003; 170:1765-71.

[22] Dalbagni G, Genega E, Hashibe M, Zhang ZF, Russo P, Herr $\mathrm{H}$ et al. Cystectomy for bladder cancer: a contemporary series. J Urol. 2001; 165(4): 1111-6.
[23] Rosario DJ, Becker M, Anderson JB. The changing pattern of mortality and morbidity from radical cystectomy. BJU Int. 2000; 85(4): 427-30.

[24] Stein JP, Lieskovsky G, Cote R, Groshen S, Feng AC, Boyd S et al. Radical cystectomy in the treatment of invasive bladder cancer: long-term results in 1,054 patients. J Clin Oncol. 2001; 19(3): 666-75.

[25] Liberman D, Lughezzani G, Sun M, Alasker A, Thuret R, Abdollah $\mathrm{F}$ et al. Perioperative mortality is significantly greater in septuagenarian and octogenarian patients treated with radical cystectomy for urothelial carcinoma of the bladder. Urology. 2011; 77(3): 660-6.

[26] Nielsen ME, Shariat SF, Karakiewicz PI, Lotan Y, Rogers CG, Amiel GE, et al. Advanced age is associated with poorer bladder cancer-specific survival in patients treated with radical cystectomy. Eur Urol. 2007; 51(3): 699-708.

[27] Shariat SF, Milowsky M, Droller MJ. Bladder cancer in the elderly. Urol Oncol. 2009; 27(6): 653-67. 